\title{
INSTRUMENTI PROCJENE GRUBIH MOTORIČKIH FUNKCIJA U DJECE S CEREBRALNOM PARALIZOM
}

\author{
ANA KATUŠIĆ ${ }^{1,2}$, DARKO MILAŠČEVIĆ ${ }^{3}$, JASMINKA GAGULA ${ }^{2}$ \\ 'Znanstveni centar izvrsnosti za temeljnu, kliničku i translacijsku neuroznanost, Hrvatski institut za istraživanje mozga, \\ Medicinski fakultet Sveučilišta u Zagrebu, kontakt: akatu@hiim.hr, ${ }^{2}$ Dnevni centar za rehabilitaciju Mali dom-Zagreb, \\ ${ }^{3} Z$ dravstveno veleučilište Zagreb
}

Primljeno: 18.03.2019.

Stručni rad

Prihvaćeno: 13.05.2019.

UDK: 616.8-009.1-053.2

https://doi.org/10.31299/hrri.55.1.6

Sažetak: Procjena u promjeni motoričke funkcije djece s cerebralnom paralizom složen je mjerni zadatak. Iako su razvijeni različiti instrumenti procjene za kvantificiranje specifičnih aspekata motoričkog ponašanja, sustavno mjerenje grubih motoričkih funkcija predstavlja zahtjevan problem u praksi. Ovaj rad kritički prikazuje valjane i klinički utemeljene instrumente procjene koji se koriste u randomiziranim kontroliranim istraživanjima na području cerebralne paralize. Razvijanje i vrednovanje odgovarajućih mjernih instrumenata važno je za procjenu znanstveno utemeljenih pristupa u habilitaciji djece s cerebralnom paralizom.

Ključne riječi: cerebralna paraliza, grube motoričke funkcije, instrumenti procjene

\section{UVOD}

Cerebralna paraliza (CP) skupina je poremećaja koja uključuje poremećaje pokreta, posture i motoričkih funkcija, a razvija se zbog oštećenja nezrelog mozga ili mozga u razvoju (SCPE, 2000). Sama procjena grubog motoričkog razvoja kod djece $s$ $\mathrm{CP}-\mathrm{om}$ zahtjevan je proces. Iako će djeca s CP-om kroz rast i razvoj doseći različite razine grubog motoričkog funkcioniranja, motorički razvoj i stjecanje motoričkih vještina skoro uvijek će biti odgođeni i ometeni.

Mjerenje funkcije, a osobito promjene $\mathrm{u}$ funkcionalnoj razini tijekom vremena, ovisi o dostupnosti instrumenata koji mogu razlikovati pojedince prema dimenziji interesa (diskriminativni indeks) ili koji mogu otkriti promjene u funkcionalnom ponašanju pojedinca tijekom vremena (evaluacijski indeks) (Kirshner i Guyatt, 1985). Općenito je valjano i pouzdano mjerenje promjene $u$ funkciji jedan od osnovnih ciljeva u vrednovanju učinaka habilitacijskih pristupa. Stoga primijenjeni instrumenti procjene grube motoričke funkcije moraju sadržavati relevantne čestice te biti osjetljivi na promjenu od kliničkog značenja u funkcioniranju djeteta s CP-om.
Cilj je rada kritički prikazati valjane i klinički utemeljene instrumente procjene za mjerenje grubih motoričkih funkcija u djece s CP-om.

\section{Klasificiranje grubog motoričkog funkcioniranja}

Najčešće korišten instrument koji opisuje grubo motoričko funkcioniranje kod djece s CP-om klasifikacijski je sustav grubih motoričkih funkcija (eng. Gross Motor Function Classification System - GMFCS) (Palisano i sur., 2008). Klasifikacijski sustav GMFCS temelji se na procjeni djetetovih trenutnih sposobnosti i ograničenja u gruboj motorici, s naglaskom na razinu samostalnosti i motoričke učinkovitosti u kretanju, sjedenju i hodanju te korištenju pomagala za kretanje i/ili dodatne tehnologije. Motoričku sposobnost djeteta razlikuje prema pet razina funkcioniranja. Klasifikacija sustava GMFCS pokazuje visoku razinu pouzdanosti i primjenjivosti za potrebe kliničke prakse, istraživanja $i$ administracije $u$ rehabilitaciji djece s CP-om (Shevell i sur., 2009).

Fokus je klasifikacije sustava GMFCS na utvrđivanju koja od razina najbolje predstavlja djetetove trenutne mogućnosti i ograničenja u gruboj 
Tablica 1. Stupnjevanje grubih motoričkih funkcija u pet razina prema GMFCS-skali za dob prije 2. godine (Russel i sur., 2000). Za dob prije 2. godine života djeteta klasifikacijski sustav GMFCS opisuje razine motoričkih mogućnosti kroz kontrolu držanja tijela te izvedbu pokreta i kretanja.

\begin{tabular}{|l|l|}
\hline GMFCS & \multicolumn{1}{|c|}{} \\
\hline Razina I & $\begin{array}{l}\text { Dijete se samostalno posjeda te sjedi dok su ruke slobodne za manipulaciju predmetima. Puže na rukama i } \\
\text { koljenima, podiže se u stojeći položaj te radi korake pridržavajući se za namještaj. Samostalno hoda bez pomoći } \\
\text { te pomagala u dobi između } 18 \text { i } 24 \text { mjeseca. }\end{array}$ \\
\hline Razina II & $\begin{array}{l}\text { Dijete sjedi koristeći ruke u funkciji potpore. Gmiže na trbuhu ili puže na rukama i koljenima. Podiže se u } \\
\text { stojeći položaj i radi korake dok se pridržava za namještaj. }\end{array}$ \\
\hline Razina III & $\begin{array}{l}\text { Dijete sjedi uz potporu u području donjeg dijela leđa. Dijete se okreće u ležećem položaju na leđa i trbuh te } \\
\text { gmiže na trbuhu prema naprijed. }\end{array}$ \\
\hline Razina IV & $\begin{array}{l}\text { Dijete ima kontrolu glave, ali u sjedećem položaju mu je potrebna potpora u području trupa. Može raditi } \\
\text { okretanje u ležećem položaju na trbuh i leđa. }\end{array}$ \\
\hline Razina V & $\begin{array}{l}\text { Fizičko oštećenje ograničava voljnu kontrolu pokreta. Ne može zadržavati kontrolu glave, trupa u ležećem } \\
\text { položaju na trbuhu i sjedećem položaju. Za okretanje u ležećem položaju potrebna mu je pomoć druge osobe. }\end{array}$ \\
\hline
\end{tabular}

motoričkoj funkciji i ne uključuje ni procjenu kvalitete izvođenja ni utjecaj kvalitete pokreta na funkciju. Naglasak je na izvođenju uobičajenih zadataka kod kuće, u školi i u svakodnevnom okruženju, a ne na zadacima koje je dijete u mogućnosti najbolje izvesti. Zbog navedenog je važno klasificirati trenutnu izvedbu u gruboj motoričkoj funkciji opservacijom djeteta u navedenim okruženjima te kroz intervju s roditeljima i/ili djetetom. Unutar svake od pet razina klasifikacijskog sustava GMFCS opisana je motorička funkcija za djecu različite dobi u sljedećim rasponima: prije 2. godine (Tablica 1), od 2. do 4. godine, od 4. do 6. godine, od 6. do 12. godine i od 12. do 18. godine (Hanna i sur., 2008). Sustav je usklađen s Međunarodnom klasifikacijom funkcioniranja, onesposobljenja i zdravlja (MKF) za djecu i mlade Svjetske zdravstvene organizacije koja je promijenila prioritete $u$ procjeni stanja pacijenta te prebacila naglasak s vrednovanja oštećenja i onesposobljenja na procjenjivanje sposobnosti i preostale funkcije djeteta (Russell i sur., 2002). Tako npr. opisi funkcioniranja za razdoblje od 6 . do 12. i od 12. do 18. godine reflektiraju potencijalni utjecaj okolinskih (npr. udaljenost do škole) i osobnih čimbenika (npr. potreba za energijom i društvene postavke) na načine kretanja djeteta.

Skala klasifikacijskog sustava GMFCS predstavlja ordinalnu skalu, bez namjere da se izjednačavaju razlike između razina ili da djeca i mladi s CP-om budu jednako raspoređeni unutar pet razina. Djeca koja imaju motoričke teškoće slične onim opisanim unutar razine i mogu općenito hodati bez poteškoća, ali s ograničenjem u pojedinim naprednijim motoričkim vještinama. Djeca čija je motorička funkcija klasificirana unutar razine V, imaju općenito velika ograničenja u sposobnosti samostalnog hodanja, čak i uz korištenje pomagala. Istraživanja valjanosti klasifikacijskog sustava grube motoričke funkcije pokazala su kako GMFCS ukazuje na značajne razlike između pojedinih razina funkcioniranja djeteta.

Klinička vrijednost navedenog sustava klasifikacije krije se u dobroj prognozi djetetove grube motoričke funkcije u kasnijoj dobi (Beckung i sur., 2007). Izrađeni percentili i referentne krivulje za svaku dobnu skupinu i razinu funkcioniranja daju mogućnost stručnjacima da međusobno, kao i zajedno s roditeljima, raspravljaju o trenutnoj razini grubog motoričkog funkcioniranja djeteta te je usporede s očekivanom razinom. Tako stručnjaci mogu predviđati potencijalne promjene tijekom razdoblja koje slijedi te prema tome odrediti ciljeve i prilagoditi okolinu za razinu djetetovog funkcioniranja.

Krivulje rasta grube motoričke funkcije pokazuju obrazac razvoja grubih motoričkih funkcija kod djece s CP-om klasificiranih unutar različitih razina GMFCS-a. Krivulje su temeljene na rezultatima mjerenja grubih motoričkih funkcija dobivenih standardiziranim testom grubih motoričkih funkcija za djecu s CP-om, tj. GMFM-testom (engl. Gross Motor Function Measure - GMFM). Navedene krivulje omogućavaju na dokazima utemeljenu prognozu napretka grube motoričke funkcije, planiranje intervencije i procjenu napretka kroz vrijeme (Rosenbaum i sur., 2002). Longitudinalno praćenje 
djece s CP-om pokazuje kako djeca na višoj razini grubog motoričkog funkcioniranja (GMFCS razine I-III) dosegnu vrhunac razvoja grubih motoričkih funkcija oko 4. ili 5. godine života što je značajno kasnije od djece s nižom razinom grubog motoričkog funkcioniranja (GMFCS razine IV i V) koji taj vrhunac dosegnu već oko 2 . godine života.

\section{TESTOVI PROCJENE GRUBIH MOTORIČKIH FUNKCIJA}

Sustav GMFCS klasificira dijete u jednu od pet razina grubog motoričkog funkcioniranja, ali kako bi se točno odredio individualan rezultat mjerenja grube motoričke funkcije, potrebno je provesti procjenu specifičnim testovima za grubu motoričku funkciju.

\section{Test grubih motoričkih funkcija - GMFM-88 i GMFM-66}

Normalan razvoj prekretnica grube motoričke funkcije opsežno je dokumentiran u literaturi što ujedno čini podlogu za pet dimenzija Testa grubih motoričkih funkcija (GMFM-test), standardiziranog testa za procjenu motoričkog statusa djece s CP-om (Russel i sur., 2002). Ovim testom možemo odrediti točan rezultat grube motoričke funkcije za dijete s CP-om. Zadaci uključuju aktivnosti u ležećem proniranom i supiniranom položaju, progresiju do okretanja, sjedenja, klečanja, puzanja i stajanja te završno hodanja, trčanja i skakanja (Russel i sur., 2002). Mjerni instrument GMFM standardiziran je za procjenu motoričkog statusa djece s CP-om i osmišljen je kao test procjene djetetove motoričke izvedbe bez ikakve pomoći ili facilitacije od strane ispitivača. Test u originalnoj izvedbi obuhvaća 88 čestica/zadataka jednake težine, podijeljenih u 5 dimenzija: (1) ležanje i okretanje; (2) sjedenje; (3) puzanje; (4) stajanje i (5) hodanje, trčanje i skakanje. Za svaku česticu unutar dimenzije dodjeljuje se ocjena na ordinalnoj skali od 0 do 3 , ovisno o opsegu aktivnosti koje dijete može izvršiti samostalno u odnosu na traženi zadatak. Nemogućnost izvedbe zadanog zadatka ocjenjuje se ocjenom 0 . Ocjena 1 predstavlja započinjanje izvedbe zadanog zadatka, dok se ocjenom 2 ocjenjuje djetetovo djelomično izvršavanje zadatka. Ocjena 3 bilježi uspješno završen zadatak od strane djeteta. Svrha korištenja ovog instrumenta procjene jest praćenje promjena u djetetovoj gruboj motoričkoj funkciji u određenom vremenskom periodu, nakon provedene intervencije $\mathrm{i} / \mathrm{ili} \mathrm{u}$ istraživanjima učinkovitosti intervencija kod djece s CP-om (Rosenbaum i sur., 2002; Bower i sur., 2001). Istraživanja pokazuju kako je GMFM-test pouzdan i koristan instrument za procjenu motoričke funkcije i ishoda tretmana djece s CP-om (Nordmark i sur., 1997). U procjeni ishoda fizioterapijskog tretmana isti se instrument pokazao kao dovoljno osjetljiv za pozitivne i negativne promjene u motoričkoj izvedbi djece s CP-om (Russell i sur., 1989). Zbog vremenske zahtjevnosti same provedbe testa od 88 čestica, autori su originalnu inačicu GMFM-testa smanjili na 66 zadataka, uz zadržavanje jednake pouzdanosti testa. Verzija testa GMFM-88, osim što je bila vremenski zahtjevnija, imala je otežavajuću okolnost nužnosti provođenja svih 88 zadataka kako bi se mogao ručno izračunati rezultat mjerenja. U slučaju da dijete odbija provesti neki od zadataka rezultat bi bio 0 što bi utjecalo na ukupni rezultat. Ovaj problem riješen je inačicom testa GMFM-66 koji je praćen računalnim sustavom za analizu rezultata provedenog testiranja (engl. Gross Motor Ability Estimator - GMAE), što je smanjilo vrijeme analize i interpretaciju rezultata. Osim što skraćuje vrijeme testiranja, inačica testa GMFM-66 omogućava dobivanje ukupnog rezultata uz minimalni broj od 13 testiranih zadataka i stvarno razlikovanje ocjene 0 - dijete ne započinje izvođenje zadataka od ocjene NT - nije testirano jer dijete odbija izvesti zadatak. Sukladno djetetovim grubim motoričkim sposobnostima uvedeni su eliminacijski zadaci testa GMFM-66 (engl. Gross Motor Function Measure 66 - Item Setts; GMGM-66-IS) koji olakšavaju izbor seta zadataka uz zadržavanje pouzdanosti rezultata mjerenja (Russell i sur., 2010).

Također jedan od načina provođenja testa jest takozvani pristup "od temeljnog do krovnog rezultata" (engl. Gross Motor Function Measure 66 Basal and Ceiling Approach; GMFM-66-B\&C), u kojem se prema djetetovoj dobi i GMFCS razini određuje početni zadatak za mjerenje. Testiranje se provodi do trenutka kada dijete od početna tri uzastopna zadatka ocijenjena ocjenom 3 (temeljni rezultat) postigne tri uzastopna zadatka ocijenjena ocjenom 0 (krovni rezultat) kada se testiranje zavr- 
šava. Broj minimalno testiranih zadataka između temeljnog i krovnog rezultata trebao bi iznositi 15 , što može isključiti djecu na krajnjem spektru grubih motoričkih vještina, tj. djecu klasificiranu na razinama GMFCS V i GMFCS I.

Oba pristupa testiranja, GMFM-66-IS i GMFM66-B\&C, točna su u procjeni rezultata GMFM-66 u jednom vremenskom razdoblju. Ukoliko je primarni cilj procjene mjerenje promjene u gruboj motoričkoj funkciji, standardni bi izbor trebala biti puna verzija testa GMFM-66. GMFM-66-IS u praksi je najčešće korištena skraćena verzija testa za djecu s unilateralnim spastičnim tipom CP-a (Avery i sur., 2013).

S druge strane verzija testa GMFM-88 svoju primjenu pronalazi primarno kod djece u ranoj razvojnoj dobi kao i kod djece s težim motoričkim teškoćama koje odgovaraju GMFCS razini IV i V. Njihove su motoričke sposobnosti postojane u manje zahtjevnim položajima te odgovaraju izvedbi motoričkih funkcija u ležećem položaju na leđima i trbuhu s okretanjem, što su uglavnom zadaci testa GMFM88. Ukoliko procjena zahtijeva uvid u motoričke sposobnosti djeteta koje koristi određeno pomagalo za kretanje, također se preporuča procjenu provesti testom GMFM-88 (Rosenabum i sur., 2002).

Na temelju Raschove analize GMFM-66 predstavlja stupnjevan pristup kvantificiranju grubih motoričkih sposobnosti kod djece s CP-om (Glazebrook i Wright, 2014; Alotaibi i sur., 2014). Rezultati mjerenja omogućavaju planiranje intervencije za unapređenje grube motoričke funkcije, temeljene na objektivnim pokazateljima, te procjenu učinka i promjene grube motoričke funkcije nakon provedenog intervencijskog razdoblja.

Prethodno spomenute krivulje motoričkog rasta i referentni percentili uvelike olakšavaju procjenu inicijalnog stanja, usporedbu testiranog djeteta $\mathrm{s}$ uzorkom djece iste GMFCS razine i dobi te planiranje ciljane intervencije (Steven i sur., 2008). Ako rezultat testa GMFM-66 u djeteta određene dobi i GMFCS razine usporedimo s krivuljama rasta grube motoričke funkcije i referentnim percentilima, možemo jasno vidjeti kako se gruba motorička funkcija testiranog djeteta kreće u odnosu na referentni okvir djece s CP-om iste dobi i klasifikacije. Referentne krivulje za GMFM-66 prema dobi i GMFCS razini napravljene su na $3,5,10,25,50,75,90,95$. i 97. percentilu. Navedeni referentni percentili proširuju klinički značaj testa GMFM-66 i klasifikacijskog sustava GMFCS pružajući prikladnu interpretaciju rezultata testa GMFM-66 unutar pojedine GMFCS razine. Percentili se trebaju koristiti zajedno uz interpretaciju sirovih rezultata testa GMFM-66 za razumijevanje promjene u gruboj motoričkoj funkciji, kao i za poimanje relativnog položaja testiranog djeteta u odnosu na djecu normativnog uzorka iste dobi i GMFCS razine (Beckung i sur., 2007). Ovakav pristup daje nam uvid u mogućnost napretka grube motoričke funkcije kroz nadolazeće intervencijsko razdoblje kod testiranog djeteta. Sveobuhvatnija analiza rezultata testa GMFM-66 i grafa zadataka prema težini izvođenja olakšava određivanje točne grube motoričke vještine koju trebamo unaprijediti u intervencijskom razdoblju koje slijedi kako bi dijete doseglo više rezultate unutar svoje skupine.

\section{Test grubih motoričkih funkcija za djecu s pridruženim cerebralnim oštećenjem vida - GMFM-88-CVI}

Kako CP osim motoričkih teškoća uključuje i pridružena neurorazvojna odstupanja kao što su oštećenje vida i sluha, komunikacije, teškoća u učenju te deficita pažnje (Mejaški-Bošnjak, 2007), pridružene neurorazvojne teškoće neophodno je uzeti u obzir prilikom procjene grubih motoričkih funkcija. Teškoće u vizualnoj percepciji, osim što mogu imati nepovoljan utjecaj na razvoj grubih motoričkih funkcija, mogu smanjiti i valjanost same procjene testom GMFM-88 u djece koja uz CP imaju i oštećenje vida. Spektar je oštećenja vida u djece s CP-om širok te uključuje različite oblike od strabizma, smanjene vidne oštrine i kontrastne osjetljivosti, nistagmusa do cerebralnog oštećenja vida (Da Costa i sur, 2004; Ghasia i sur., 2008). Cerebralno oštećenje vida vizualna je disfunkcija koja se ne može povezati s okularnim oštećenjem, već je posljedica oštećenja vidnog puta i vidnih struktura nakon križanja vidnog živca (Dutton i sur., 2001). Djeca s CP-om i pridruženim cerebralnim oštećenjem vida pokazuju usporeniji razvoj svakodnevnih i socijalnih vještina te mobilnosti u usporedbi $\mathrm{s}$ djecom s CP-om bez cerebralnog oštećenja vida ( $\mathrm{Da}$ Costa i sur, 2004; Ghasia i sur., 2008).

Uzimajući u obzir da se u $30 \%$ djece s CP-om opaža cerebralno oštećenje vida (Ghasia i sur., 2008), kreirana je verzija testa za djecu s CP-om i 
cerebralnim oštećenjem vida (engl. cerebral visual imapirments - CVI), GMFM-88-CVI (Salavati i sur, 2015). Navedena modificirana verzija sadrži sve čestice izvornog testa, no prilagodba se očituje u verbalnim uputama, manualnoj podršci te vrsti opreme i okruženju. Predmeti koji se koriste tijekom procjene visokog su kontrasta, žarkih boja te su izvor zvučnog podražaja kako bi se privukla pažnja i kretanje djeteta prema njima (Salvati i sur., 2015). Rezultati provedenog istraživanja pokazala su kako djeca s CP-om i pridruženim cerebralnim oštećenjem vida postižu bolji ukupni rezultat na testu GMFM-88-CVI u usporedbi s rezultatima koje postižu na verziji testa GMFM-88 (Salvati i sur., 2017). To govori u prilog boljoj valjanosti testa GMFM-88-CVI za procjenu grubih motoričkih funkcija u djece s CP-om i cerebralnim oštećenjem vida. Modificirana verzija testa prilagođenim predmetima potiče dijete $\mathrm{s}$ CP-om i cerebralnim oštećenjem vida na pokret te mu omogućava uspješniju izvedbu motoričkog zadatka. Stoga je izgledno kako je niži rezultat na testu GMFM-88 odraz samog oštećenja vida, a ne motoričkih oštećenja.

\section{Test naprednih motoričkih vještina - Challenge-test}

Korisnost GMFM-testa za identificiranje naprednih vještina grube motorike i dokumentiranje objektivnih pokazatelja napretka djece klasificirane na razini GMFCS I ograničena je (Glazebrook i Wright, 2014; Alotaibi i sur., 2014). Istraživanja pokazuju kako tri četvrtine djece na razini GMFCS I dosegnu vrhunac izvedbe na GMFM-testu, u dobi od 7 godina (Morris i Bartlett, 2004). Unatoč visokim rezultatima na GMFM-testu, djeca klasificirana na razini GMFCS I imaju velik potencijal za unapređenje motoričkih vještina koje su usmjerene prema izvedbi vještina poput trčanja, skakanja i vještina s loptom (kontrola lopte) koje facilitiraju sudjelovanje s vršnjacima (Shevell i sur., 2009). Nedostatak instrumenta koji opsežno mjeri ove napredne vještine predstavljao je ograničenje kako za procjenu prije planiranja intervencije (u svrhu postavljanja ciljeva) tako i za mjerenje ishoda intervencije (Glazebrook i Wright, 2014).

Upravo stoga osmišljen je Challenge-test kako bi se nadomjestio navedeni nedostatak u mjerenju naprednih motoričkih vještina kod djece $\mathrm{s} \mathrm{CP}-\mathrm{om}$
(Wilson i sur., 2011). Challenge-test obuhvaća procjenu motoričkih sposobnosti preciznosti i brzine kroz 25 zadataka temeljenih na vještinama potrebnim za sudjelovanje u programu tjelesnog odgoja i aktivne igre (Wilson i sur., 2011). Namjera je da stručnjaci mogu koristiti rezultate Challenge-testa za planiranje tretmana kroz vještine koje mogu vrednovati te koje imaju potencijal razvoja uz primjerene intervencije (Beckung i sur., 2007). Challenge-test je razvijen u skladu s idejom da bi se mjerenje motoričkih funkcija trebalo više usmjeriti na prepoznavanje snaga i mogućnosti za povećanje razine sudjelovanja u životu, a manje prema određivanju onesposobljenja (Lam i sur., 2015). Tijekom svake procjene Challenge-testom, bilo da se provodi u kliničke ili istraživačke svrhe, važno je procijeniti vrhunsku izvedbu preciznosti i brzine kako bi se dobila dosljedna slika djetetovih sposobnosti. Challengetest obuhvaća procjenu motoričkih vještina koje se smatraju važnima za sudjelovanje djece i mladih u školskim i rekreativnim aktivnostima (1), koje se fokusiraju na smanjene sposobnosti brzine, ravnoteže i koordinacije, tipične za djecu s CP-om na razini GMFCS I (2) i koje povezuju pokrete gornjih i donjih udova te izvedbu tzv. dvostrukih zadataka (3). Challenge-test mogu provoditi stručnjaci na području pedijatrijske neuromotoričke habilitacije s iskustvom u korištenju GMFM-testa (Wright, 2016). Sama provedba testa zahtijeva od 30 do 40 minuta. Kao preduvjet za sudjelovanje u procjeni dijete treba biti sposobno samostalno i ujednačeno prohodati $0.45 \mathrm{~m}$ sa stopalima unutar označene staze za vrijeme svakog koraka (Gibson i sur., 2016). Challenge-test je pouzdan instrument procjene za mjerenje naprednih motoričkih vještina te postiže visoku razinu dosljednosti kod više ispitivača i kod inicijalnog i finalnog testiranja, uz više rezultate testa na finalnom testiranju, što ga čini klinički održivim za detekciju promjene (Wright i sur., 2017).

\section{Test kvalitete pokreta - QFM-test}

Djeca s CP-om klasificirana na GMFCS razini I imaju velik potencijal za napredovanje u izvedbi vještina kao što su trčanje, skakanje, preskakanje te vještina s loptom koje olakšavaju i povećavaju razinu sudjelovanja s vršnjacima (Morris i Bartlett, 2004; Shevell i sur., 2009; Capio i sur., 2012). Mjerenja kritičkih aspekata izvedbe, poput procjene motorič- 
kih vještina koje su usmjerene na produkciju (usredotočuju se na broj uspješnih ponavljanja, vrijeme potrebno za izvedbu ili postignute udaljenosti) snažno su povezana s funkcionalnim sposobnostima i razinom sudjelovanja kod djece s CP-om, dok su mjerenja motoričkih vještina usmjerenih na proces, tj. na kvalitetu pokreta, najprimjerenija za pružanje uvida u temeljno onesposobljenje (Capio i sur., 2011).

Upravo je u procjeni motoričkih funkcija djece s CP-om jedan od velikih izazova objektivno mjerenje kvalitete pokreta. Procjena kvalitete tradicionalno se temeljila na opisnim nalazima stručnjaka te je značajno ovisila o iskustvu i samoj edukaciji stručnjaka koji piše nalaz, pa je samim time bila i poprilično subjektivna. Test kvalitete pokreta (engl. The Quality Function Measure - QFM-test) prvi je instrument procjene koji mjeri kvalitetu pokreta kod djece s CP-om te je izrađen na temelju testa GMFM-66 (Wright i sur., 2014). QFM-test mjeri kvalitetu pokreta djece s CP-om u dobi od 5. godina života, koja su klasificirana na GMFCS razinama I, II i III. Test se sastoji od 37 zadataka iz domena GMFM-a: stajanje i hodanje/trčanje/skakanje. U svrhu vrednovanja koristi se videosnimka djetetove izvedbe na GMFM zadacima iz navedenih domena. Procjena omogućava bolje razumijevanje načina djetetova kretanja te strategija i izazova pri kretanju. Test procjenjuje pet domena, odnosno obilježja kvalitete pokreta: (1) poravnanje gornjeg i donjeg dijela tijela; (2) koordinacija, (3) disociranost pokreta; (4) stabilnost i (5) prijenos težine. Bodovanje se provodi na skali od 0 do 3, jednako kao i na GMFM-testu. Unutar domene poravnanja promatra se prilagodba ili međusobno postavljanje dijelova tijela. U okviru aspekta koordinacije procjenjuje se glatko i kontrolirano korištenje pokreta u motoričkoj izvedbi uzimajući u obzir vrijeme, brzinu, preciznost, usmjerenost, snagu i amplitudu pokreta. Za domenu disociranih pokreta procjenjuju se izolirani pokreti jednog dijela tijela koji su neovisni od drugog dijela tijela (npr. pokreti jedne noge neovisno o pokretima druge noge) te pokreti koji kombiniraju komponente različitih motoričkih obrazaca (npr. ekstenzija kuka s fleksijom u koljenu). Aspekt stabilnosti procjenjuje položaj tijela u prisutnosti ometajućih sila. Za domenu prijenos težine procjenjuju se pokreti koji uključuju premještanje težišta tijela, njegov smjer i količinu prijenosa, u bilo kojem od četiri smjera u odnosu na tijelo (posteriorno, lateralno, anteriorno ili vertikalno) ili u bilo kojoj kombinaciji navedenih smjerova (Wright i sur., 2014). Nakon provedene procjene bodovanje se provodi zasebno za svaku domenu. Interpretacija rezultata QFM-testa pouzdana je i valjana što omogućava procjenu načina kretanja djece i mladih s CP-om. Ishodi procjene identificiraju područja funkcioniranja koja je potrebno ciljati kroz intervenciju kako bi se unaprijedila kvaliteta motoričke kontrole (Capio i sur., 2011). Dobiveni se rezultati QFM-testa analiziraju zajedno s rezultatima na testu GMFM-66 te se uzajamno koriste za planiranje intervencije, ovisno o djetetovoj GMFCS razini i rezultatima unutar pet domena kvalitete pokreta. Ovakav način procjene omogućava ciljano planiranje intervencije prema djetetovim specifičnim potrebama za unapređenje grube motorike i kvalitete izvedbe (Wright, 2016).

\section{ZAKLJUČAK}

Provedba i analiza rezultata prikazanih objektivnih testova procjene omogućuje stručnjacima ciljano planiranje intervencije prema djetetovim potrebama za unapređenje grube motorike, naprednih motoričkih vještina, kvalitete pokreta, ali i za sudjelovanje djeteta u sportsko-rekreativnim i socijalnim aktivnostima.

Nesustavna primjena navedenih instrumenata procjene ne dovodi u pitanje samo utemeljenost intervencije kod djece s CP-om, već i njen učinak na razinu funkcioniranja i sudjelovanja djeteta $u$ aktivnostima zajednice i svakodnevnog života. S druge strane sustavan pristup kliničkoj procjeni pridonosi habilitacijskoj praksi koja je utemeljena na dokazima. Stoga odabir primjerenog instrumenta procjene, s obzirom na sposobnosti i na pridružene teškoće u kliničkoj slici, predstavlja važan korak u praćenju promjena funkcionalnog statusa djeteta s CP-om, kao i u vrednovanju učinkovitosti dostupnih intervencija na području habilitacije motoričkih funkcija.

Ovaj rad omogućio je ZCI-Neuro - Znanstveni centar izvrsnosti za temeljnu, kliničku i translacijsku neuroznanost, projekt KK.01.1.1.01.0007. 
Hrvatska revija za rehabilitacijska istraživanja 2019, Vol 55, br. 1, str. 59-67

\section{LITERATURA}

Alotaibi, M., Long, T., Kennedy, E., Bavishi, S. (2014). The efficacy of GMFM-88 and GMFM-66 to detect changes in gross motor function in children with cerebral palsy (CP). a literature review, Disability and Rehabilitation, 36(8), 617-627.

Avery, L.M., Russell, D.J., Rosenbaum, P.L. (2013). Criterion validity of the GMFM-66 item set and the GMFM-66 basal and ceiling approaches for estimating GMFM-66 scores. Developmental Medicine and Child Neurology, 55, 534-538.

Beckung, E., Carlsson, G., Carlsdotter, S., Uvebrant, P. (2007). The natural history of gross motor development in children with cerebral palsy aged 1 to 15 years, Developmental Medicine and Child Neurology, 49, 751-756.

Bower, E., Michell, D., Burnett, M., Campbell, M. J., McLellan, D.L. (2001). Randomized controlled trial of physiotherapy in 56 children with cerebral palsy followed for 18 months. Developmental Medicine and Child Neurology, 43(1), 4-15.

Capio, C., Sit, C., Abernethy, B. (2011). Fundamental movement skills testing in children with cerebral palsy. Disabilities and Rehabilitation, 33, 2519-2528.

Capio, C., Sit, C., Abernethy, B., Masters, R. (2012). Fundamental movement skills and physical activity among children with and without cerebral palsy. Research in Developmental Disabilities, 33, 1235-1241.

Da Costa, M.F., Salmao, S.R., Berezovsky, A., De Hero, F.M., Ventura, D.F. (2004). Relationship between vision and motor impairment in children with cerebral palsy: new evidence from electrophysiology. Behavioural Brain Research, 149, 145-150.

Dutton, G.N., Jacobson, L.K. (2001). Cerebral visual imapirment in children. Seminars in Neonatology, 6, $477-485$.

Ghasia, F., Burnstroom, J., Gordon. M. i Tyschen, L. (2008). Frequency and severity of visual sensory and motor deficit sin children with cerebral palsy: gross motor function classification scale. Investigative Ophtalmology and Visual Science, 49, 572-580.

Gibson, B.E., Wright, V., Mistry, B. (2016). Administration of the Challenge Module (Research Version). Guidelines for Engaging with Children and Families. Engagement Guidelines for website April 2016. Toronto, Canada: Bloorview Research Institute, Holland Bloorview Kids Rehabilitation Hospital.

Glazebrook, C.M., Wright, V. (2014). Measuring Advanced Motor Skills in Children With Cerebral Palsy: Further Development of the Challenge Module. Pediatric Physical Therapy, 26, 201-213.

Hanna, S.E., Bartlett, D.J., Rivard, L.M., Russell, D.J. (2008). Reference curves for the gross motor function measure: Percentiles for clinical description and tracking over time among children with cerebral palsy. Physical Therapy, $88,596-607$.

Kirshner, B., Guyatt, G.H. (1985). A methodologic framework for assessing helath indices. Journal of Chronic Disabilities, 38, 27-36.

Lam, C., Mistry, B., Walker, J., Wright, F. (2015). Reliability of the Challenge Module in measuring advanced motors skills in children with cerebral palsy. Developmental Medicine and Child Neurology, 57, 28.

Mejaški Bošnjak, V. (2007). Dijagnostički pristup ranom otkrivanju neurorazvojnih odstupanja. Paediatria Croatica, 51 (Supl 1), 105-110.

Morris, C., Bartlett, D. (2004). Gross Motor Function Classification System: impact and utility. Developmental Medicine and Child Neurology, 46, 60-65.

Nordmark, E., Hagglund, G., Jarnlo, G. (1997). Reliability of the gross motor function measure in cerebral palsy. Scandinavian Journal of Rehabilitation Medicine, 29(1), 25-28.

Palisano, R.J., Rosenbaum, P., Bartlett, D., Livingston, M.H. (2008). Content validity of the expanded and revised Gross Motor Function Classification System. Developmental Medicine and Child Neurology, 50, 744-750. 
Rosenbaum, P.L., Russell, D.J., Cadman, D.T., Gowland, C., Jarvis, S., Hardy, S. (1990). Issues in measuring change in motor function in children with cerebral palsy: A special communication. Physical Therapy, 70(2), $125-131$.

Rosenbaum, P., Walter, S., Hanna, S., Palisano, R., Russell, D., Wood, E., Bartlett, D., Galuppi, B. (2002). Prognosis for gross motor function in cerebral palsy: creation of motor development curves. JAMA, 288(11), 1399-1400.

Russell, D.J., Rosenbaum, P., Cadman, D., Gowland, C., Hardy, S., Jarvis, S. (1989). The gross motor function measure: a means to evaluate the effects of physical therapy. Developmental Medicine and Child Neurology, 31(3), 341-352.

Russell, D.J., Avery, L.M., Rosenbaum, P.L., Raina, P.S., Walter, S.D., Palisano, R.J. (2000). Improved scaling of the gross motor function measure for children with cerebral palsy: evidence of reliability and validity. Physical Therapy, 80, 873-885.

Russell, D.J., Rosenbaum, P.L., Avery, L.M., Lane, M. (2002). Gross Motor Function Measure (GMFM-66\&GMFM-88) User's Manual. Lodnon: Mac Keith Press

Russell, D.J., Avery, L.M., Walter, S.D., Hanna, S.E., Bartlett, D.J., Rosenbaum, P.L., Palisano, R.J., Gorter, J.W. (2010). Development and validation of item sets to improve efficiency of administration of the 66-item Gross Motor Function Measure in children with cerebral palsy. Developmental Medicine and Child Neurology, 52, 48-54.

Salvati, M., Krijnen, W.P., Rameckers, E.A.A., Looijestijn, P., Maathius, C.G.B., Schans van der, C.P. i sur. (2015). Reliability of the modified gross motor function measure-88 (GMFM-88) for children with cerebral palsy and cerebral visual impairments: A preliminary study. Research in Developmental Disabilities, 45-46, 32-48.

Salvati, M., Rameckers, E.A.A., Waninge, A., Krijnen, W.P., Steenbergen, B., Schans van der, C.P. (2017). Gross motor function in children with spastic cerebral and cerebral visual impairments: A comparison between outcomes of the original and the cerebral visual impairment adapted Gross Motor Function Measure-88 (GMFM-88-CVI). Research in Developmental Disabilities, 60, 269-276.

Shevell, M.I., Dagenais, L., Hall, N., Repacq, C. (2009). The relationship of cerebral palsy subtype and functional motor impairment: a population-based study. Developmental Medicine and Child Neurology, 51, 872-877.

Steven, E.H., Bartlett, D.J., Rivard, L.M., Russell, D.J. (2008). Tabulated reference percentiles for the 66-item Gross Motor Function Measure for use with children having cerebral palsy. London: Can Child Centre for Childhood Disability Research, McMaster University.

Surveillance of Cerebral Palsy in Europe. (2000). A collaboration of cerebral palsy surveys and registers. Developmental Medicine and Child Neurology, 42, 816-824.

Wilson, A., Kavanaugh, A., Moher, R., McInroy, M., Gupta, N., Salbach, N.M., Wright, F.V. (2011). Development and pilot testing of the challenge module: a proposed adjunct to the Gross Motor Function Measure for high-functioning children with cerebral palsy. Physical \& Occupational Therapy in Pediatrics, 31(2), 135-149.

Wright, V., Rosenbaum, P., Fehlings, D., Mesterman, R., Breuer, U., Kim, M. (2014). The Quality FM: Reliability and discriminant validity of a new measure of quality of gross motor movement in ambulatory children with cerebral palsy. Developmental Medicine and Child Neurology, 56, 770-778.

Wright, V. (2016). Introduction to the Challenge for children with cerebral palsy. Course handouts. Korčula Island, Croatia: Akademija za razvojnu rehabilitaciju.

Wright, V., Ying Lam, Y., Mistry, B., Walker, J. (2017). Evaluation of the reliability of the Challenge when used to measure advanced motor skills of children with cerebral palsy. Physical Occupation Therapy Pediatrics, $18,1-13$. 


\section{MEASUREMENTS OF GROSS MOTOR FUNCTION FOR CHILDREN WITH CEREBRAL PALSY}

Abstract: Assessment of changes in motor function in children with cerebral palsy is a complex measurement task. Although a variety of tests have been developed to quantify specific aspects of motor behaviour, systematic measurement of gross motor function is still a challenge. This paper critically reviews valid and clinically based evaluative measures that are used in randomised controlled trials in the field of cerebral palsy. The development and validation of responsive evaluative measures is essential for the assessment of evidence-based approaches in habilitation of children with cerebral palsy.

Key words: cerebral palsy, gross motor functions, measure instruments 